\title{
EXPERIMENTAL TESTBED FOR ACCESS POINT SELECTION IN IoT WiFi NETWORKS
}

\author{
V. Lavrukhin ${ }^{1}$, A. Lezhepekov ${ }^{2}$, A. Vladyko ${ }^{2}$ \\ ${ }^{1}$ ER-Telecom Holding, Perm, 614990, Russia \\ ${ }^{2}$ The Bonch-Bruevich Saint-Petersburg State University of Telecommunications, \\ St. Petersburg, 193232, Russia \\ Article info \\ Article in English
}

For citation: Lavrukhin V., Lezhepekov A., Vladyko A. Experimental Testbed for Access Point Selection in IoT WiFi Networks // Proceedings of Educational Institutes of Communication. 2017. Vol. 3. Iss. 2. PP. 102-112.

Abstract: This paper analyzes WiFi access point selection mechanisms used by IoT WiFi devices. A testbed for experimental setup is proposed. The testbed includes several WiFi access points, WiFi controller and WiFi network analyzer. More than 900 measurements covering 19 test cases are made. It is shown that an received signal strength indicator is the primary criterion used by the IoT WiFi device for access point selection during connection procedure.

Keywords: WiFi, access point, IoT, RSSI, testbed.

\section{ЭКСПЕРИМЕНТАЛЬНЫЙ СТЕНД ДЛЯ ПРОВЕДЕНИЯ ИССЛЕДОВАНИЙ ПО ВЫБОРУ WіFі-СЕТИ ІоТ-УСТРОЙСТВАМИ}

\author{
В. Лаврухин ${ }^{1}$, А. Лежепёков ${ }^{2 *}$, А. Владыко ${ }^{2}$ \\ ${ }^{1}$ АО «ЭР-Телеком Холдинг», Пермь, 614990, Российская Федерация \\ ${ }^{2}$ Санкт-Петербургский государственный университет телекоммуникаций им. проф. М.А. Бонч-Бруевича, \\ Санкт-Петербург, 193232, Российская Федерация \\ *Адрес для переписки: anton.lezhepekov@mail.ru
}

\section{Информация о статье}

УДК 621.396

Язык статьи - английский

Ссылка для цитирования: Lavrukhin V., Lezhepekov A., Vladyko A. Experimental Testbed for Access Point Selection in IoT WiFi Networks // Труды учебных заведений связи. 2017. Том 3. № 2. C. 102-112.

Аннотация: $B$ статье проводится анализ механизмов, используемьх для организации беспроводной WiFi-cети IоT-устройствами. Все измерения произведень средствами испытательного стенда, включающего в себя несколько точек доступа WiFi, WiFi-контроллер u WiFi-анализатор сети. В результате проведения более 900 испытаний в 19 различных условиях установлена зависимость между мощностью принимаемого сигнала RSSI и выбором предпочтительной точки доступа. Предложены параметры Channel Utilization и STA count в качестве дополнительных критериев, влияющцих на выбор оптимальной точки доcmyna. 
Ключевые слова: WiFi, точка доступа, IoT, RSS, экспериментальный стенд.

\section{Introduction}

Interaction of IoT $^{1}-$ devices with each other and with outside environment is carried out via organization of wired as well as wireless networks [1]. The basic concept of IoT implies mobility and compactness of end-user devices, thus, the basic means of interaction are wireless access networks. In this article IEEE 802.11 standard is considered as wireless technology for interaction of IoT-devices [2]. The concept of organization of corporate WiFi networks implies centralized management of access points with the help of controller of this network. Access points (AP) are combined into seamless network with one service set identity (SSID). Subscriber station (SS) receives a list of WiFi network SSIDs available for connection. SS operating system programmatically sorts the list of available networks according to criteria specified by application developers. Thus, user does not have any possibility to choose AP independently among corporate networks and to change the sorting algorithm for available WiFi APs. The used side-effect frees the user from decisionmaking related to the choice of particular AP, instead providing algorithm on program side. Parameters used for relevant AP selection algorithm - access points meeting user's requirements concerning throughput in uplink and downlink and average response time, are not standardized and determined by operating system developers at application level [3].

Objective of present research is determination of wireless WiFi connection parameters by means of experiments affecting the sorting process of the list of available APs by end-user device in the context of Android and iOS operating systems. Absence of recommendations for relevant WiFi network determination of existing group of IEEE 802.11 standards results in uncertainty during formation of the list of APs available for user connection. The problem of existing WiFi APs selection algorithm is in delegation of vendors for criteria selection, which are the base of ranking process, to developers of high-level applications, which are not always experts in the sphere of wireless data transfer - WiFi [4].

By 2020 there are expected 13.5 billion of IoT devices, a part of which competes with each other for the selection of optimal WiFi AP. Inability of relevant AP identification will result in uneven distribution of user devices across APs, and it can lead to service denial with the loss of ability for information exchange within IoT. At the present moment, this problem is solved at the level of WiFi network controller, if network creation includes this controller and there is enabled the load balancing function. In all other cases, the problem of uneven distribution of user IoT-devices at APs has a great impact on network capacity [5].

In this article, the results of 950 experiments confirm the hypothesis of the use of $\mathrm{RSSI}^{2}$ as the main criterion for relevant network selection, that it takes into account only physical bases of radio signal propagation, but it does not take into ac-

\footnotetext{
${ }^{1}$ IoT - Internet of Things

${ }^{2}$ RSSI - Received Signal Strength Indication
} 
count behavioral factors of network users (for example, number of connected users and their activity).

\section{Background}

Nowadays, IEEE 802.11-2012 standard influences algorithm of user stations connection to WiFi access point without explicit criteria specification for relevant network selection, thus, developers of operating systems and high-level applications tacitly use the RSSI [6]. The received signal strength does not take into account noise level of this frequency channel, on which $\mathrm{SNR}^{3}$ parameter is based [6, 7]. Absence of possibility to change the level of electromagnetic noisiness during optimal access point selection results in multiple interpretation of problem solution concerning relevant WiFi network determination.

\section{RSSI experiment}

In this article, we will consider WiFi network consisting of controller WiFi Ruckus Wireless ZoneDirector 1100, two APs Ruckus Wireless ZoneFlex 7372, switch D-Link DGS-1100-24P, to which there will be connected user IoT-devices Xiaomi and Apple with operating systems Android and iOS, respectively.

RSSI experiment is necessary for confirmation of hypothesis about exclusive effect of RSSI signal strength. Ranking process of access points is based on arranging the list of available access points as far as RSSI indicator decreases:

$$
R S S I=P_{0}-10 \cdot n \cdot \log _{10} \frac{d}{d_{0}}[d B m],
$$

where $d$ - distance from device to transmitter, $\mathrm{m} ; d_{0}$ - distance from device to access point, $\mathrm{m} ; n$ - signal power-loss ratio in environment; $P_{0}$ - reference power, $\mathrm{dBm}$.

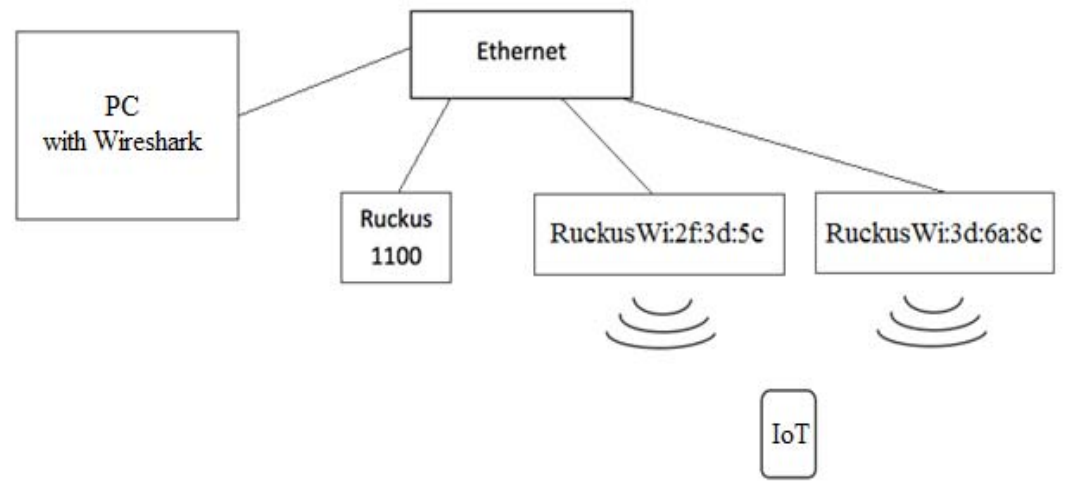

Fig. 1. Scheme of experimental unit
The present experiment was implemented with the use of test unit shown in Fig. 1. Two APs Ruckus Wireless ZoneFlex 7372 are connected into one network under the control of controller Ruckus Wireless ZoneDirector 1100 and broadcasting on the same SSID ${ }^{4}$ «TEST». Xiaomi Home and Apple iHome

\footnotetext{
${ }^{3}$ SNR - Signal to Noise Ratio

${ }^{4}$ SSID - Service Set Identifier
} 
IoT-device was connected to «TEST» network at the same distance from two APs. The experimental procedure involves 20 different states simulated with the use of test unit shown in Fig. 1. In open field conditions in absence of competing devices capable of creating electromagnetic interference (WiFi networks, microwave ovens, medical devices and others), there is generated WiFi network open for public access at frequency band of $5 \mathrm{GHz}$. Two APs broadcast on the same SSID «TEST», thus, providing the right of choice not to user, but to algorithm embed into UE. During experiment, two APs will have different parameters allowing indirectly determining the factor influenced this or that outcome of connection process. UE is at the same distance from both APs for contest in equal conditions. In case of initial conditions, mobile device is not familiar with network. User connects to the only possible SSID «TEST» without any passwords and with the help of parallel logging Wireshark determines AP MAC-address in favor of which there was made a choice. Tp-Link TLWDN3200 was used as adapter for frames capturing on user computer with Wireshark installed.

During experiments, there were examined 19 cases with 50 experiments in each. Every case mutually eliminates the influence of access point configuration on relevant WiFi network selection algorithm. In this article, there will be presented 4 of 50 experiments of several most important cases in the form of Matlab graph:

1) Two APs transmit with the same maximum power level of $20 \mathrm{dBm}$ each on 36 and 52 frequency channels (and vice versa). There are no end-user devices connected to APs.

2) There is the same experimental setup as in case 1, but the power level of APs was reduced to minimum level of $1 \mathrm{dBm}$.

3) Two APs transmit with different power levels of 1 and $10 \mathrm{dBm}$ (and vice versa). There are no end-user devices connected to APs.

4) Two APs transmit with the same power level of $10 \mathrm{dBm}$ each on 36 and 52 frequency channels (and vice versa). The first AP has 10 connected SS devices, the second AP has no any connected SS devices (and vice versa).

5) Two APs transmit with the same power level of $10 \mathrm{dBm}$ each on 36 and 52 frequency channels (and vice versa). The first AP has one connected SS device with iperf traffic generator started to make the maximum channel load, the second AP has no any connected SS devices (and vice versa).

6) Two APs transmit with different power levels of 1 and $10 \mathrm{dBm}$ on 36 and 52 frequency channels (and vice versa). The first AP has one connected SS device with iperf traffic generator started to make the maximum channel load, the second AP has no any connected SS devices (and vice versa).

Results of experiments from Wireshark via LUA language were ported to Matlab for subsequent graph plotting and contest winner determination. The dashed red line indicates the authentication moment. Before each experiment, on user deviced there were deleted all previously saved WiFi networks.

\footnotetext{
${ }^{5}$ UE - User Equipment
} 
Case 1. In this test case both APs broadcast at the same maximum power level of $20 \mathrm{dBm}$; there are no other connected users. RuckusWi:3d:6a:8c and RuckusWi:2f:3d:5c use 36 and 52 frequency channels, respectively (and vice versa). Objective of this case is determination of dependence of AP selection on frequency channel number.

Results of Case 1. Processing of 50 results in 50 cases showed (Fig. 2) the absence of dependence of access point selection on frequency channel number during transmitting with maximum power level. Thus, in 50 out of 50 experiments, the fundamental criterion for access point selection was RSSI level. These results are independent from changing APs between frequency channels. UE change did not influence the preferred AP selection.

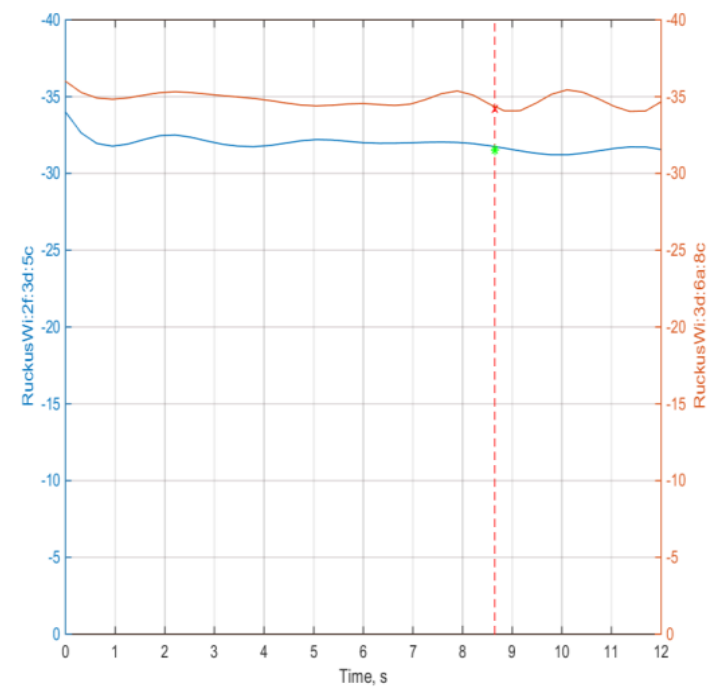

Fig. 2a. Experiment No. 17

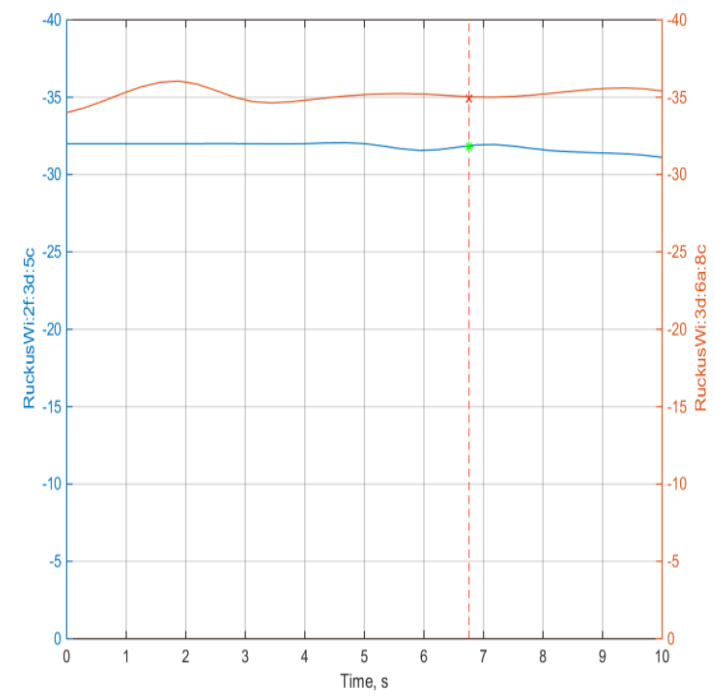

Fig. 2c. Experiment No. 24

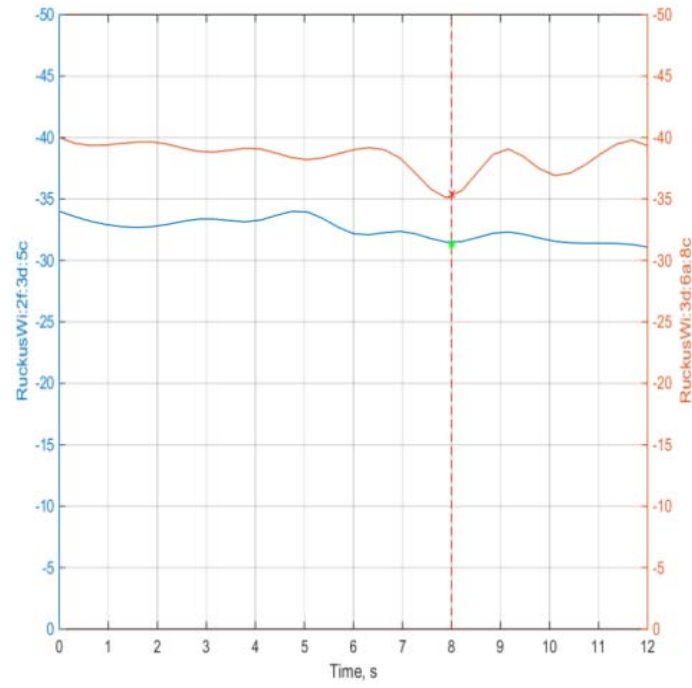

Fig. 2b. Experiment No. 13

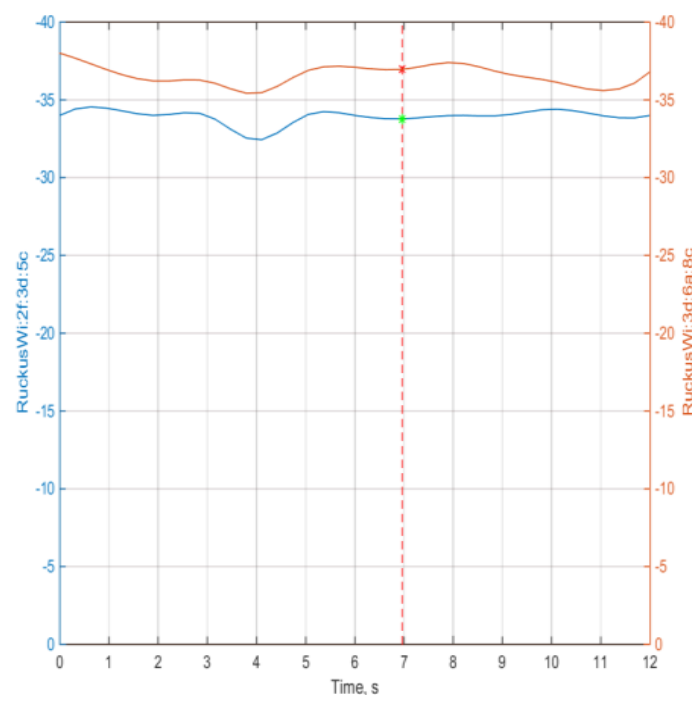

Fig. 2d. Experiment No. 44

Case 2. In this test case both APs broadcast at the same minimum power level of $1 \mathrm{dBm}$; there are no other connected users. RuckusWi:3d:6a:8c and Ruckus- 
Wi:2f:3d:5c use 36 and 52 frequency channels, respectively (and vice versa). Objective of this case is the same as in case 1 .

Results of Case 2. Processing of 50 results in 47 cases showed (Fig. 3) the absence of dependence of AP selection on frequency channel number during transmitting with minimum power level. Thus in 47 out of 50 experiments there won the AP with the highest RSSI level; exchange of frequency channels did not influence the contest outcome. UE change did not influence the preferred AP selection.

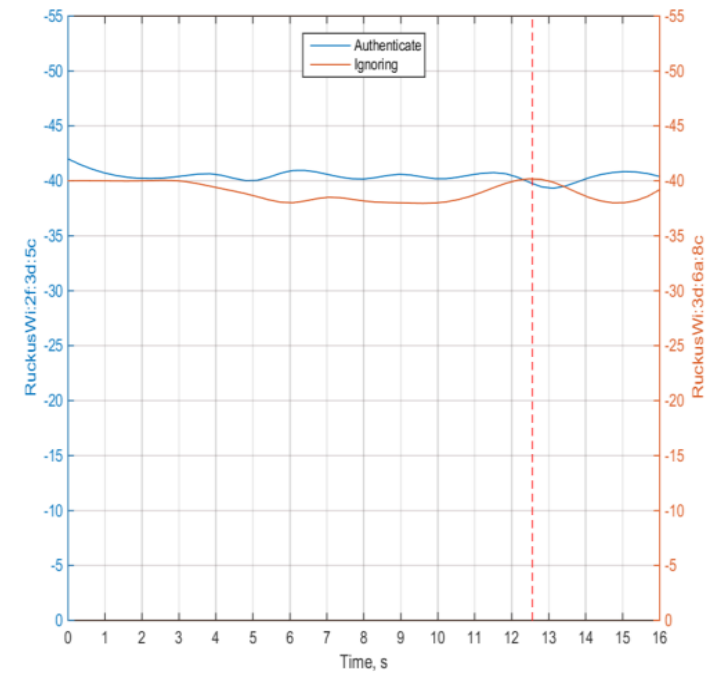

Fig. 3a. Experiment No. 8

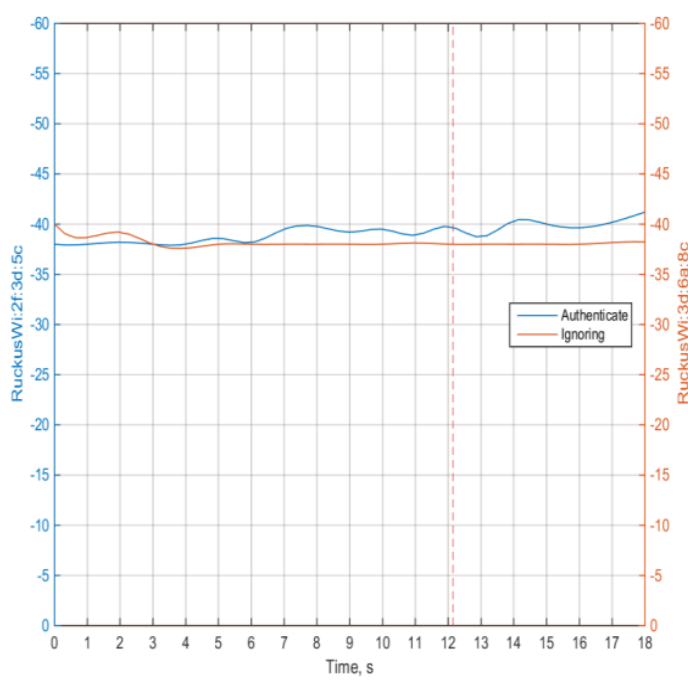

Fig. 3c. Experiment No. 31

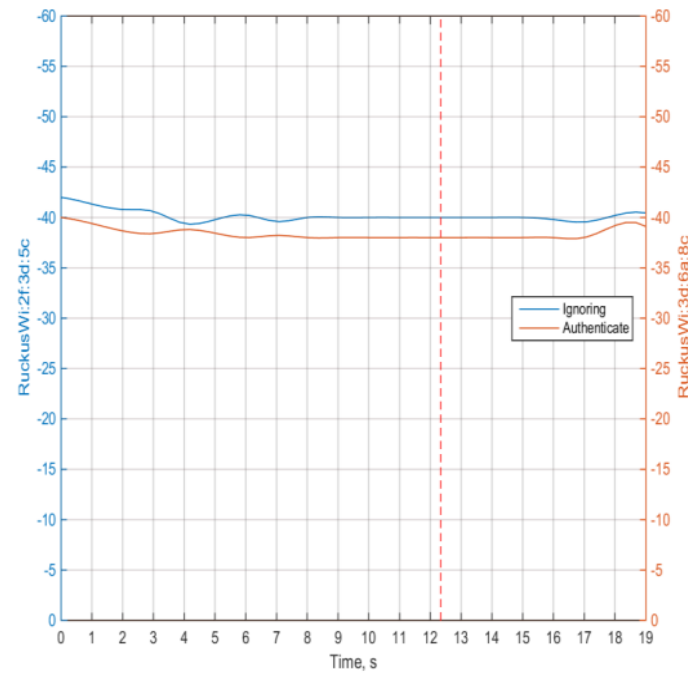

Fig. 3b. Experiment No. 24

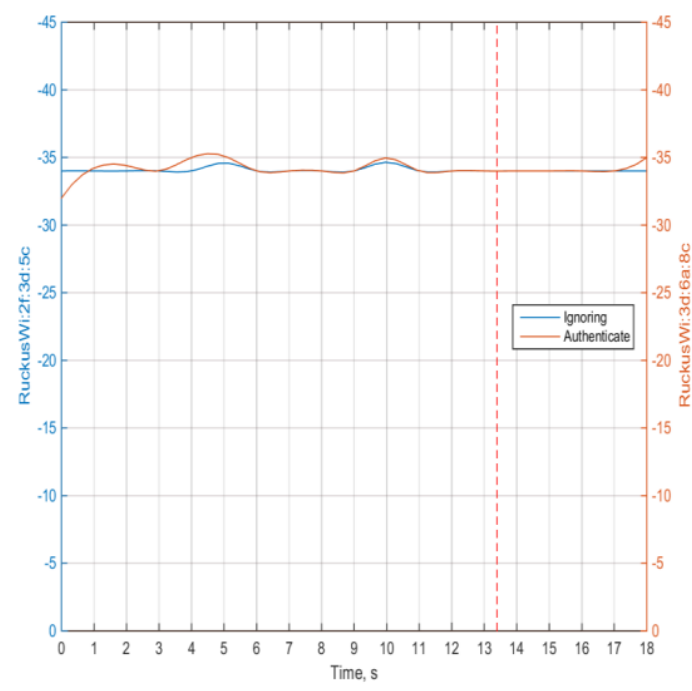

Fig. 3d. Experiment No. 10

Case 3. In this case both APs transmit with different power levels; there are no other connected users. RuckusWi:3d:6a:8c and RuckusWi:2f:3d:5c use 48 and 36 frequency channels and power levels of $1 \mathrm{dBm}$ and $10 \mathrm{dBm}$ respectively (and vice versa).

Results of Case 3. Processing of 50 experiment results of 50 cases showed (Fig. 4) the presence of dependence of access point selection on transmit power level. The result of 50 implemented experiments showed that 50 connections 
were on access point with 10-time higher power level. Thus, in 50 out of 50 experiments, there won the access point with the highest RSSI level; the change of transmit power and number of frequency channel did not result in change of preferred AP selection. UE change did not influence the preferred AP selection.

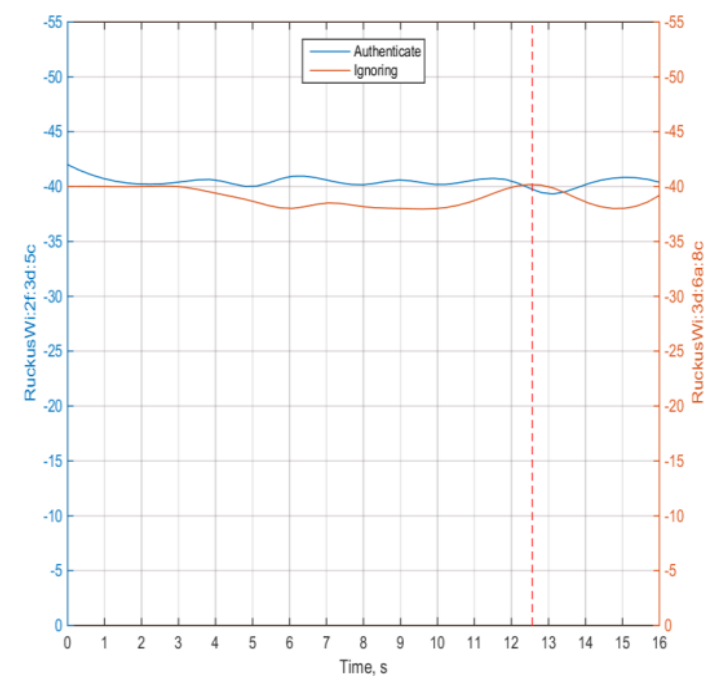

Fig. 4a. Experiment No. 8

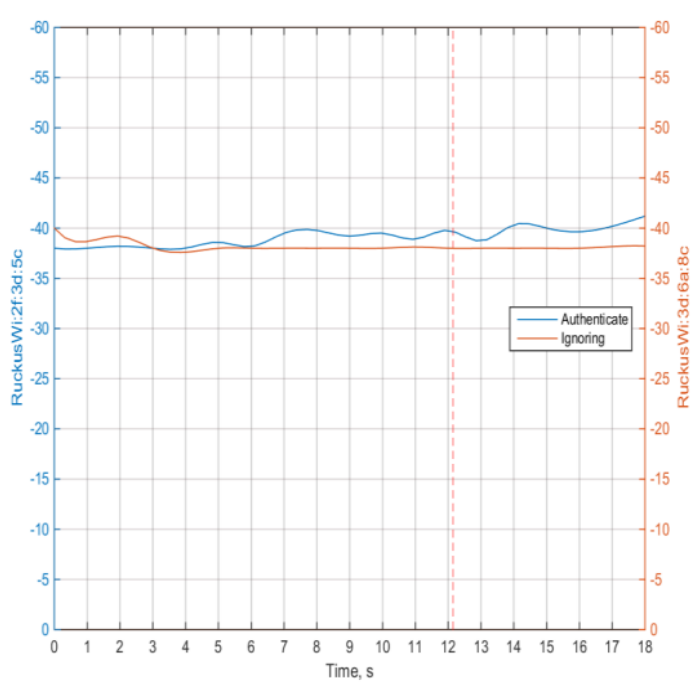

Fig. 4c. Experiment No. 31

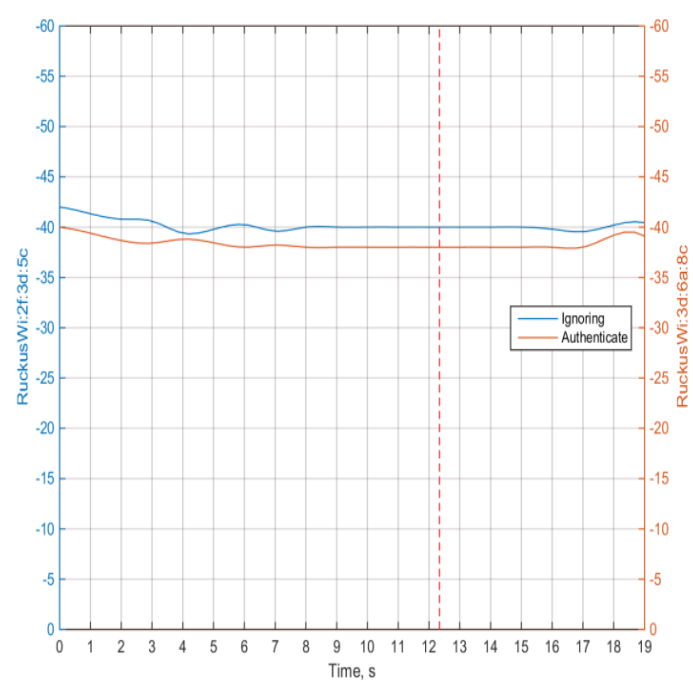

Fig. 4b. Experiment No. 24

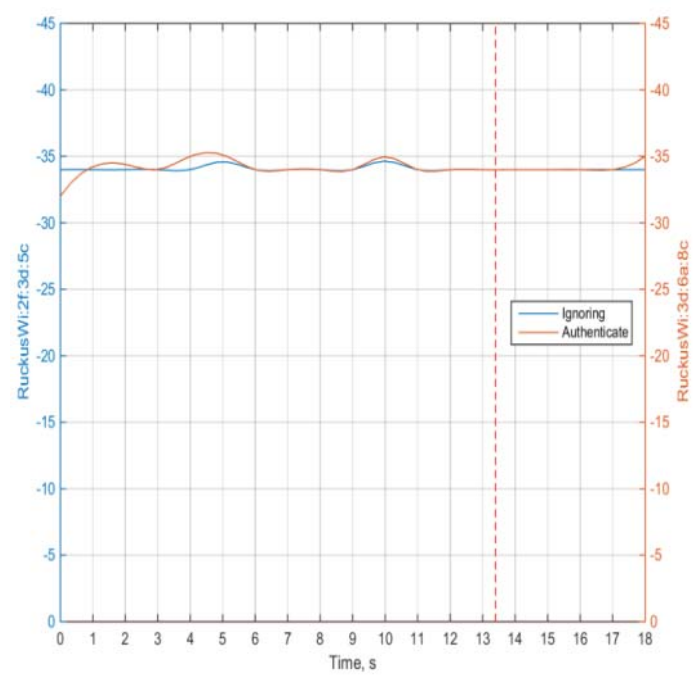

Fig. 4d. Experiment No. 10

Case 4. Objective of this case is determination of dependency of AP selection on number of users connected to the AP. Compared with case 1 , there were set the same values of transmit power of $10 \mathrm{dBm}$ for both APs and there were connected 10 other SSs to the first APs (and then to the second AP).

Results of Case 4. Processing of 50 experiment results in 42 cases showed (Fig. 5) the absence of influence of connected (to the AP) SSs on AP selection in Android and iOS. Thus, in $84 \%$ of experiments there won the access point with the highest RSSI level; the number of connected SSs to the AP did not influence the final choice. UE change did not influence the preferred AP selection. 


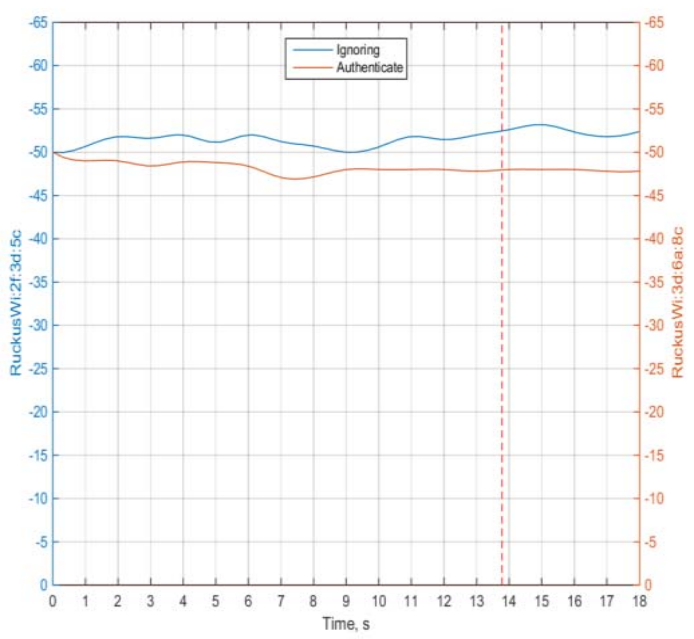

Fig. 5a. Experiment No. 6

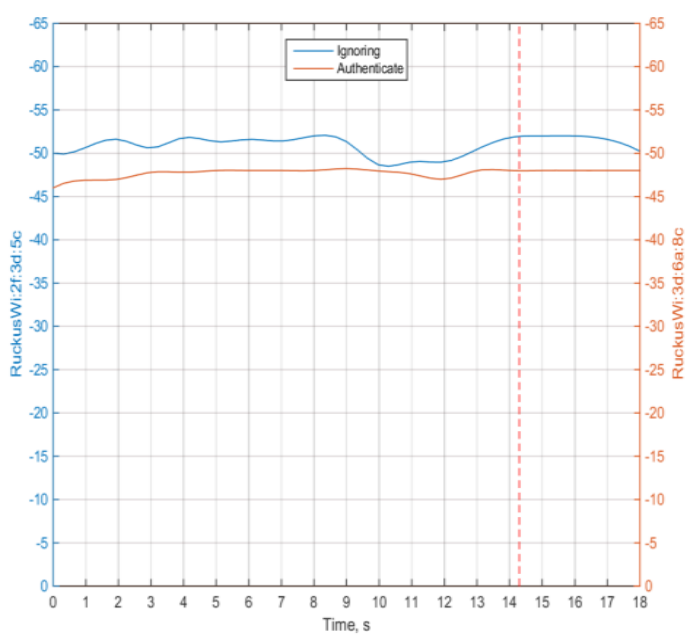

Fig. 5c. Experiment No. 31

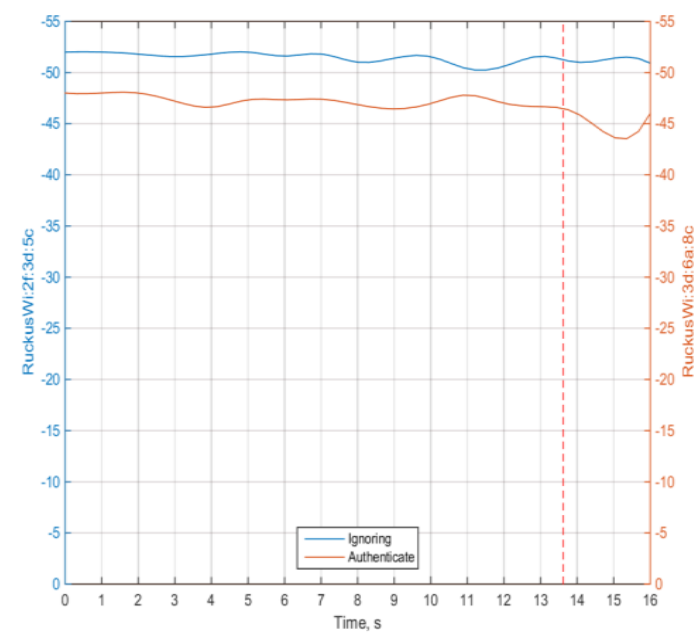

Fig. 5b. Experiment No. 1

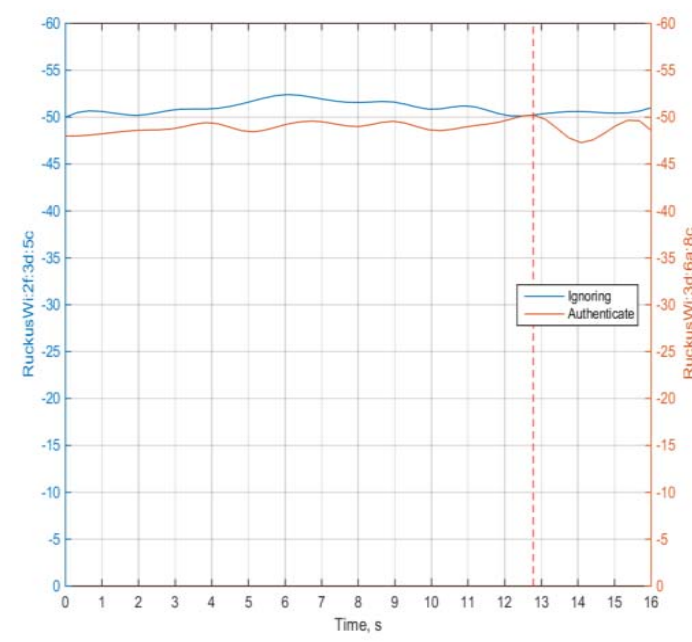

Fig. 5d. Experiment No. 40

Case 5. Objective of this case is determination of dependency of AP selection on traffic load in the frequency channel. Compared with case 4 (same transmit power of $10 \mathrm{dBm}$ on both APs) there was iperf load on the first AP (and then on the second AP). Iperf generated udp stream between SS connected to AP and PC in the wired part of the testbed. This stream occupied more than $90 \%$ of airtime of the frequency channel used by the AP.

Results of Case 5. Processing of 50 experiment results in 38 cases showed (Fig. 6) the absence of influence of frequency channel load on AP selection in Android and iOS devices. The difference of power levels from access points on receiving side at the same initial configuration is explained by physical conditions of environment. Thus, in $76 \%$ of experiments, there won the AP with the highest RSSI level; traffic generation by iperf for AP channel did not influence the final choice. 


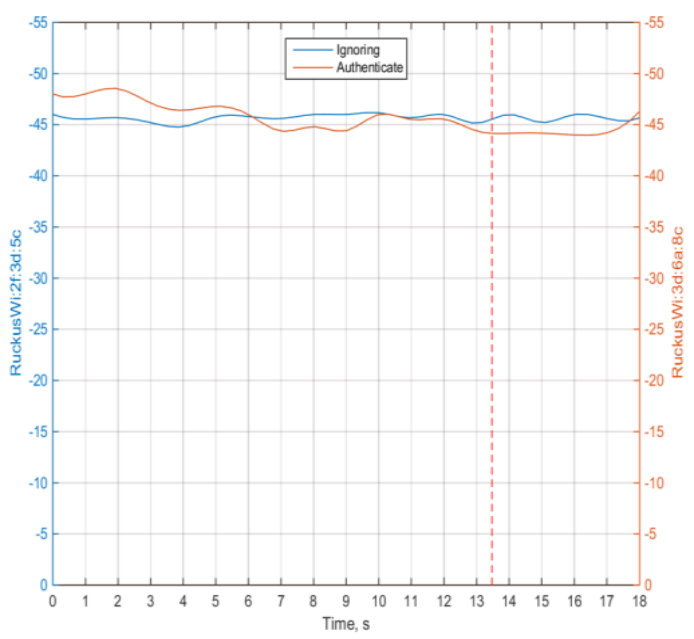

Fig. 6a. Experiment No. 2

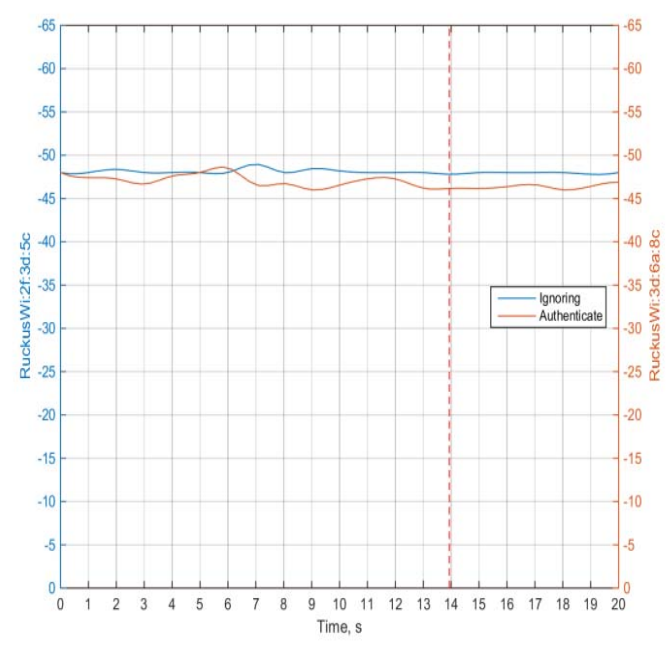

Fig. 6c. Experiment No. 4

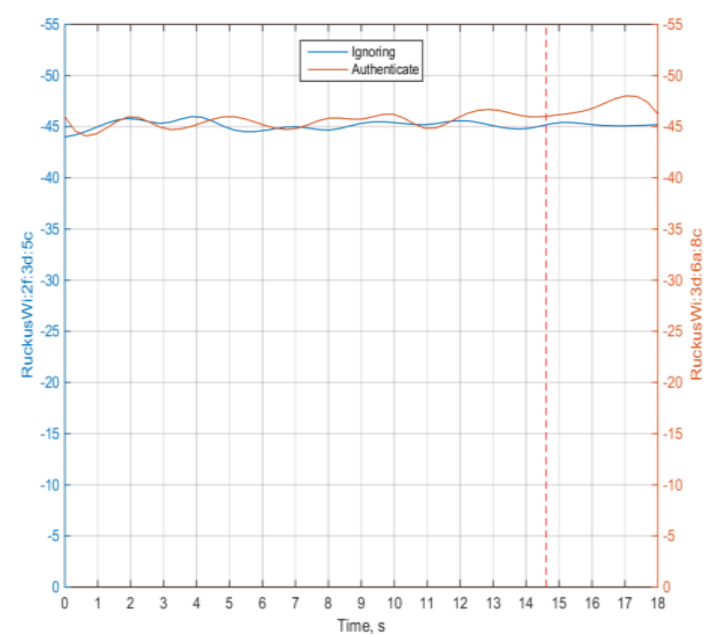

Fig. 6b. Experiment No. 3

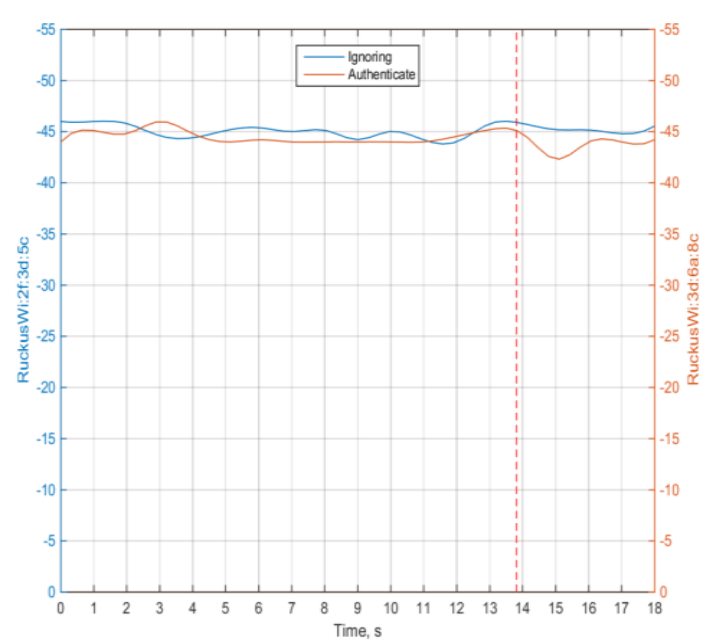

Fig. 6d. Experiment No. 5

Case 6. Objective of this case is determination of dependency of AP selection on traffic load in the frequency channel. Compared with case 5 there are set different power levels on APs: RuckusWi:2f:3d:5c - $1 \mathrm{~dB}$, RuckusWi:3d:6a:8c - $10 \mathrm{~dB}$. Traffic load was applied to the AP with reduced power level.

Results of Case 6. Processing of 50 experiment results in all 50 cases showed (Fig. 7) the absence of influence of AP channel load on AP selection in Android and iOS devices. The result of 50 implemented experiments showed that 50 connections were on AP with 10-time higher power level (RuckusWi:3d:6a:8c) independent of the channel load. Thus, in 50 out of 50 experiments, there won the AP with the highest RSSI level; traffic generation by for AP did not influence the final choice. 


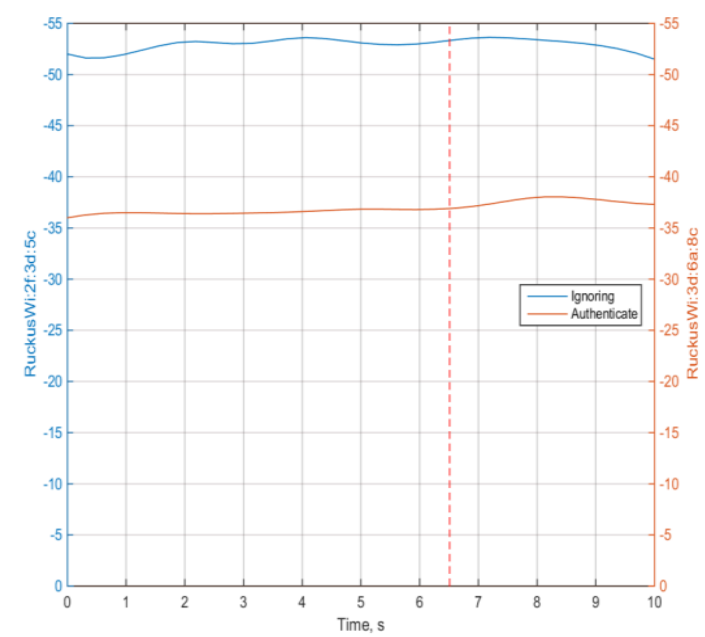

Fig. 7a. Experiment No. 2

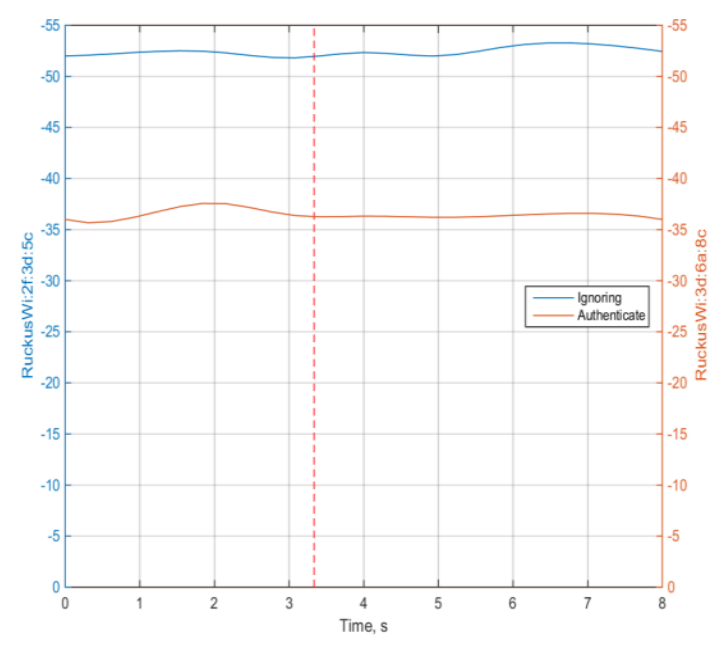

Fig. 7c. Experiment No. 3

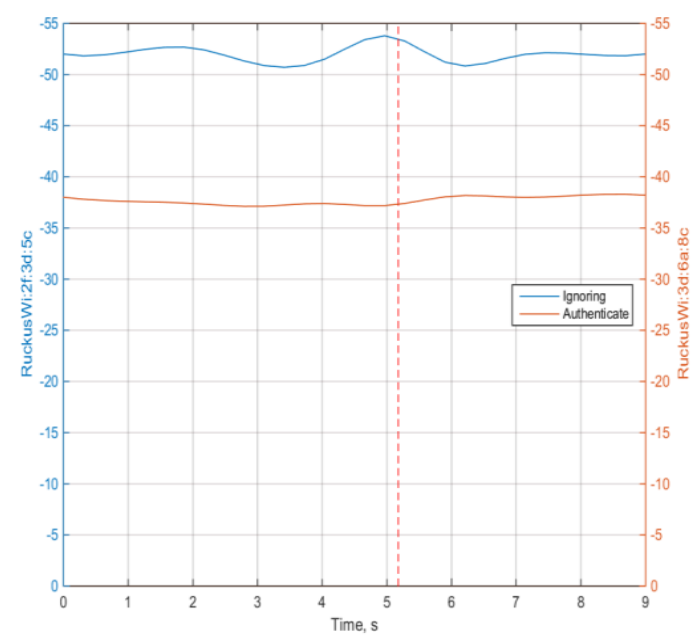

Fig. 7b. Experiment No. 23

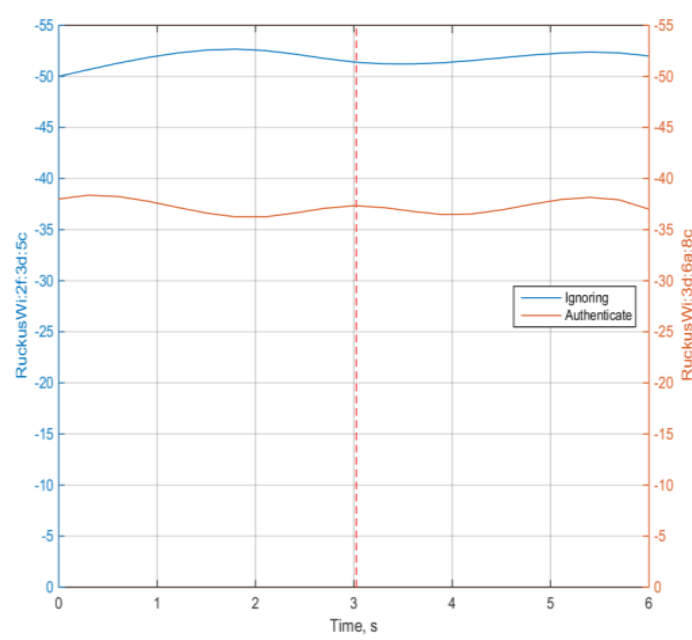

Fig. 7d. Experiment No. 46

\section{Results of experiments}

Considering all the tests the winner in 885 out of 950 experiments was AP with higher RSSI level in relation to other WiFi AP. This is more than $93 \%$ of choices. Thus, in overwhelming majority the choice of IoT-device is based on RSSI level. In the present experiment, there were examined 19 different cases demonstrating the influence of RSSI parameters, number of frequency channel, SSs count and channel load on access point selection.

The main problem of such algorithm is low correlation dependence of delay and user throughput on RSSI level. The presence of electromagnetic interference sources worsens SNR indicator, but RSSI rests the same, reducing the benefit of use of existing AP ranking algorithm. The presence of another SSs and high channel load are also constraint factors for such algorithm. The use of the number of connected users (STA Count) and frequency channel utilization (Channel Utilization) parameters for AP selection would provide more objective information related to connection 
quality. Thus, specified list of wireless WiFi networks in radio coverage zone will undergo further sorting according to its parameters responsible for wireless network quality [8]. It should be noted that the extended mechanism does not solve the problem interference, but it extends mathematical model suggesting to attack the problem of relevant network selection by increasing the number of program criteria without any hardware upgrade [9].

\section{Conclusion and future work}

In result of investigational study, there have been determined the criteria underlying $\mathrm{WiFi}$ access point selection by IoT user devices.

As part of implemented experiments, there has been proven the prevalent use of received signal strength (RSSI) as fundamental criterion for WiFi access point selection. The detailed study of $802.11 \mathrm{k}$ specification will allow offering new approaches to formation of relevant list of WiFi access points due to the use of Channel Utilization and STA Count parameters containing the number of connected user stations.

The motivation of this work is jogging a WiFi community including software developers to use more sophisticated algorithm for AP selection by end-user devices, especially in the IoT world. For the future work we will compare different complex algorithms for AP selection proposed by researchers.

\section{References}

1. Zanella A., Bui N., Castellani A., Vangelista L., Zorzi M. Internet of Things for Smart Cities // IEEE Internet of Things Journal. 2014. Vol. 1. Iss. 1, PP. 22-32.

2. Vladyko A., Paramonov A., Kirichek R., Koucheryavy A. Using the IEEE 802.11 Family of Standards for Communication Between Robotic Systems // Advances in Intelligent Systems Research. 2016. Vol. 133. PP. 153-157.

3. Andreev S., Gerasimenko M., Galinina O., Koucheryavy Y., Himayat N., Yeh S.P., Talwar S. Intelligent Access Network Selection in Converged Multi-Radio Heterogeneous Networks // IEEE Wireless Communications. 2014. Vol. 21. Iss. 6. PP. 86-96.

4. Khan M.O., Qiu L. Accurate WiFi Packet Delivery Rate Estimation and Applications // IEEE Infocom 2016 - The 35th Annual IEEE International Conference on Computer Communications. 2016. PP. 1-9.

5. Kirichek R., Paramonov A., Vladyko A., Borisov E. Implementation of the Communication Network for the Multi-Agent Robotic Systems // International Journal of Embedded and RealTime Communication Systems. 2016. Vol. 7. Iss. 1. PP. 48-63.

6. Luong P., Nguyen T.M., Le L.B., Đào N.D., Hossain E. Energy-Efficient WiFi Offloading and Network Management in Heterogeneous Wireless Networks // IEEE Access. 2017. Vol. 4. PP. 10210-10227.

7. Lavrukhin V. An Overhead Analysis of Access Network Query Protocol (ANQP) in Hotspot 2.0 Wi-Fi Networks // 13th International Conference on ITS Telecommunications (ITST). 2013. PP. 266-271.

8. Lavrukhin V., Simonina O., Volodin E. An Experimental Study of the Key QoS Parameters in Public Wi-Fi Networks // 6th International Congress on Ultra Modern Telecommunications and Control Systems and Workshops (ICUMT). 2014. PP. 198-203.

9. Lezhepekov A., Letenko I., Vladyko A. Software-Defined Routing in Convergent LTE/WiFi Networks // IEEE Conference of Russian Young Researchers in Electrical and Electronic Engineering (EIConRus). 2017. PP. 173-175. 